\title{
Partial control and learned helplessness in rats: Control over shock intensity prevents interference with subsequent escape
}

\author{
LAUREN B. ALLOY and PHILIP J. BERSH \\ University of Pennsylvania, Philadelphia, Pennsylvania 19174 \\ and Temple University, Philadelphia, Pennsylvania 19122
}

\begin{abstract}
The effect upon subsequent escape acquisition of control over shock intensity in the absence of control over other shock characteristics was examined. Pretreatment involved random shocks of 1.6 and $.75 \mathrm{~mA}$ at a density of about $10 / \mathrm{min}$. The experimental group could avoid the higher shock intensity if they leverpressed at least once every $15 \mathrm{sec}$. Yoked and noshock rats completed the triadic design. Experimental and yoked animals received all scheduled shocks. Triads were later tested for FR 2 shuttlebox escape at either the $.75 \mathrm{~mA}$ (low) or $1.6 \mathrm{~mA}$ (high) intensity. During testing, avoidance rats performed as well as noshock rats at the low intensity and escaped even more rapidly at the high intensity. Yoked rats showed interference at both intensities, with interference very marked, including many failures to escape, at the low intensity. These findings indicate that control over shock intensity, by itself, is sufficient to prevent learned helplessness and suggest that control over any salient characteristic of shock may be sufficient for immunization.
\end{abstract}

Prior exposure of organisms to inescapable and unavoidable aversive events leads to subsequent interference with the acquisition of escape/avoidance behavior. Such interference, referred to as "learned helplessness" (Maier, Seligman, \& Solomon, 1969; Seligman, Maier, \& Solomon, 1971), has been demonstrated in many organisms across a wide variety of situations (see Maier \& Seligman, 1976). According to Maier and Seligman (1976), learned helplessness requires that an organism perceive that reinforcers are uncontrollable, i.e., that their occurrence is independent of behavior. Learning that reinforcers are response-independent is postulated to result in the expectation that this will hold true in the future. In turn, it is this expectation which is the basis for the response initiation, associative, and emotional deficits which characterize the subsequent behavior of organisms exposed to uncontrollable events.

Uncontrollability, the primary condition for the development of learned helplessness, has been formally defined as the equal probability of reinforcement given the presence vs. the absence of any response (Maier \& Seligman, 1976). In aversive helplessness experiments, uncontrollability, in practice, has meant that subjects have had no influence on any characteristic of the reinforcer, including its onset or offset. Under

This research was supported by a National Institute of Mental Health Predoctoral Fellowship, MH-07284-01, to the first author and by a grant-in-aid from Temple University to the second author. Requests for reprints should be sent to Lauren B. Alloy, who is now at the Department of Psychology, Northwestern University, 1859 Sheridan Road, Evanston, Illinois 60201. these conditions, they show interference with later acquisition of escape or avoidance behavior (e.g., Hiroto \& Seligman, 1975; Jackson, Maier, \& Rapaport, 1978; Kelsey, 1977; Maier \& Testa, 1975; Seligman \& Beagley, 1975; Seligman \& Maier, 1967). Alternatively, other subjects in these experiments could terminate the aversive stimulus, thus controlling its duration and reducing its intensity to zero. Such control has been found to prevent subsequent interference.

The present experiment was designed to determine how control over shock intensity, in the absence of control over shock occurrence or any other characteristic of shock, will affect later acquisition of escape behavior. Bersh and Alloy (1978) have recently found that animals will learn to avoid on the basis of a reduction in shock intensity to a lower, though still aversive, value with no influence of responding on either the onset or offset of shock. Since this level of control is less than that involved in previous learned helplessness experiments for animals in the escape/avoidance group, perhaps it might lead to a degree of interference with later escape conditioning that is intermediate between the effect shown by animals which have no control over any aspect of shock and animals never exposed to shock. Such a finding would give rise to the provocative possibility that subsequent interference covaries with the degree of behavioral control over reinforcement available in prior learning situations. On the other hand, control over shock intensity alone may be sufficient to prevent any interference. The latter result would suggest that control over any salient characteristic of an aversive reinforcer is sufficient to prevent later interference and 
perhaps to "immunize" (Seligman \& Maier, 1967; Seligman, Rosellini, \& Kozak, 1975) an organism against learned helplessness.

\section{METHOD}

\section{Subjects}

Thirty-six naive male Sprague-Dawley rats, 90 days old and weighing $350-360 \mathrm{~g}$ upon arrival at the laboratory, were housed individually. Throughout the experiment, rats were maintained on ad-lib food and water in their home cages. They were run at the same time each day during the light period of their 12-h light/ dark cycle.

\section{Apparatus}

The apparatus consisted of two distinct and separate units. Training was administered in three experimental chambers (Lehigh Valley Electronics Model 11414), consisting of Plexiglas sidewalls and ceiling, stainless steel front and rear walls, and a grid floor. The internal dimensions were $30.2 \mathrm{~cm}$ long, $24.0 \mathrm{~cm}$ wide, and $36.8 \mathrm{~cm}$ high. A stainless steel lever (LVE Model 1352), requiring a force of approximately $10 \mathrm{~g}(.1 \mathrm{~N})$ to depress and measuring $2.7 \mathrm{~cm}$ wide and $.9 \mathrm{~cm}$ in thickness, protruded $2.5 \mathrm{~cm}$ through the front wall. The lever center was located $3.0 \mathrm{~cm}$ above the grid floor, $3.5 \mathrm{~cm}$ from the rightmost sidewall. Stainless steel grid bars, $.5 \mathrm{~cm}$ in diameter, mounted perpendicular to the sidewalls, and spaced $1.8 \mathrm{~cm}$ apart (center to center), provided the shock delivery surface. Constant-current ac shocks of $.5 \mathrm{sec}$ duration and either .75 or $1.6 \mathrm{~mA}$ intensity, measured at the grids, were delivered through an LVE shock scrambler, Model 1311SS, in series with a $150 \mathrm{kQ}$ resistor. White masking noise of $70 \mathrm{~dB}$ delivered through a large speaker to the experimental room as a whole was constantly present throughout each experimental session. A punched-tape reader and standard switching relay circuitry located in an adjacent room supplied programming and controlled shock presentation.

Testing was administered in three $19.0-\mathrm{cm}$-wide $\times 22.5-\mathrm{cm}$ high $\times 46.0-\mathrm{cm}$-long two-way shuttleboxes consisting of stainless steel walls and a Plexiglas ceiling. The shuttleboxes were contained in $42 \times 62 \times 76 \mathrm{~cm}$ plywood sound-attenuating cubicles. Each shuttlebox was divided into two halves by a stainless steel partition which had a $6 \times 7 \mathrm{~cm}$ rounded archway cut out of it. Each half of the shuttlebox chamber had 10 stainless steel grids, $.5 \mathrm{~cm}$ in diameter and $.95 \mathrm{~cm}$ from center to center, serving as the floor through which shock was delivered. Each half of the shuttlebox was in contact with a microswitch which could terminate shock when an animal crossed from one side of the shuttlebox to the other side and then back again (FR 2). Either a .75- or a 1.6-mA scrambled constant-current ac shock was delivered from a $600-\mathrm{V}$ transformer through a limiting resistor to the grid floor on both sides of the shuttlebox. Shock pulsated on and off five times per second. Animals were always run with the room lights off. White masking noise of $70 \mathrm{~dB}$ and a 120 -V houselight were constantly present throughout each session. The houselights were mounted in the ceiling of each chamber and the white noise was delivered individually to each chamber through speakers suspended from the sound-attenuating cubicles directly above the houselight. In addition, white noise was also delivered through a large speaker to the experimental room as a whole.

\section{Procedure}

Training, which began at Temple University, followed a 7-day period of adjustment to the colony room conditions. Thirty-six rats were randomly divided into six groups of six animals each. The between-subjects design was a 3 by 2 factorial in which the variables were: (1) type of training (avoidance (A) of high-intensity shocks in favor of low-intensity shocks, yoked $(Y)$ training with shocks of both intensities, or no (N) shocks); and (2) shock intensity during testing (low or high).

\section{Training}

Intensity avoidance groups. Animals in these groups were ex posed to a procedure (see Bersh \& Alloy, 1978) in which shock intensity was contingent upon the rat's behavior, while shock probability was response-independent. Shocks occurred at random intervals throughout the session. Shock probability was approximately $.33 / 2 \mathrm{sec}$, or an average of about 10 shocks $/ \mathrm{min}$. A daily session lasted $100 \mathrm{~min}$; thus, each rat received approximately 1,000 shocks/session. At the start of a session, shocks were $1.6 \mathrm{~mA}$ (high shock). The animal was required to make two leverpress responses with an interresponse time (IRT) equal to or less than $15 \mathrm{sec}$ in order to introduce a period during which .75-mA shocks (low shock) might occur. As long as the rat's IRT did not exceed $15 \mathrm{sec}$, the low-shock period was in effect. Lapse of the IRT limit introduced a period during which high shocks might occur. However, an animal might still avoid high-intensity shock if it responded twice with an IRT equal to or less than $15 \mathrm{sec}$ before the next scheduled shock occurred. Avoidance training continued for 9 to 18 sessions. Within these limits, the number of sessions was determined by an animal's performance. If a rat maintained itself in the low-shock condition for at least $85 \%$ of four consecutive sessions, training was terminated at that point (minimum of 9 sessions). Otherwise, training lasted for the maximum of 18 sessions. Rat 24 failed to meet the criterion, but was run for only 16 days due to equipment failure.

Yoked groups.Each rat in Group $Y$ was yoked to a rat in Group A for shock probability and intensity. Thus, each animal in the yoked groups received shocks at the rate of about $10 / \mathrm{min}$ at the same time and with the same intensity as its avoidance partner. As a result, yoked rats were exposed to shocks which were response independent not only with respect to probability of occurrence, but with respect to intensity. Although the lever was present throughout training, leverpresses were, of course, ineffective. Yoked rats were run on this procedure for 9-18 days, depending upon the performance of their avoidance partner.

No-shock groups. Rats in the no-shock groups were placed in the experimental chambers for the 100 -min daily sessions, but re ceived no shocks. They were run for 9-18 days, depending upon the performance of the avoidance member of the triad.

\section{Testing}

When each avoidance rat met the criterion, provided at least 9 training days had occurred, or at the end of 18 training days if it failed to meet the criterion, it was transported to the University of Pennsylvania for testing along with its yoked and noshock partners. Twenty-four hours after training, the rats in each triad received 5 FR 1 escape trials in the shuttlebox, during which a crossing from one side to the other terminated shock. If an animal failed to cross within $60 \mathrm{sec}$, shock terminated automatically and a 60 -sec latency was recorded. Immediately after these FR 1 trials, each triad was given 35 FR 2 escape trials, during which two crossings (back and forth) were required to terminate shock. If an animal failed to perform the FR 2 shuttle response within $60 \mathrm{sec}$, shock terminated automatically and a 60 -sec latency was recorded. For half of the rats in Groups $A, Y$, and $\mathrm{N}$, the shock intensity during the shuttlebox test was $.75 \mathrm{~mA}$ (low). For the other half, shock intensity was $1.6 \mathrm{~mA}$ (high). The intertrial interval had a mean of $60 \mathrm{sec}$, with a range of 10 to $110 \mathrm{sec}$.

\section{RESULTS}

\section{Training}

Figure 1 presents the daily record of the percentage which low-intensity shocks constituted of all shocks received by each avoidance animal. Since the procedure insured that animals received all scheduled shocks, this figure may be interpreted to represent the percen- 


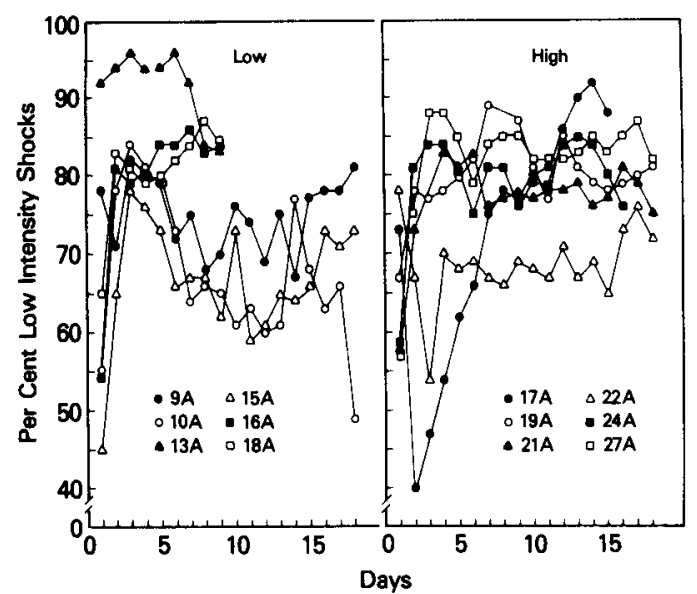

Figure 1. The number of low-intensity shocks as a percentage of the total number of shocks received during dally training sessions by the avoidance animals. The left panel provides data for the animals exposed to low-intensity shock $(.75 \mathrm{~mA})$ and the right panel data for the animals exposed to high-intensity shock (1.6 mA) during the later shuttlebox test.

tage of potential high-intensity shocks avoided and is, therefore, a measure of avoidance performance. Rats 13,16 , and 18 met the criterion of maintaining themselves in the low-shock condition for at least $85 \%$ of each of the last four sessions within the minimum period of 9 days. These animals had terminal performances of approximately $85 \%$ avoidance. The remaining avoidance animals tested at the low intensity showed great variability in their avoidance performance, with the percentage of low-intensity shocks fluctuating, for the most part, between $60 \%$ and $80 \%$. The performance of rat 10 , after attaining a peak of almost $85 \%$ avoidance, deteriorated progressively until it reached its low point of less than $50 \%$ avoidance on the last training day. The only animal in the high-shock group to meet the criterion was rat 17 , which required 15 days. The remaining animals in this group, with the exception of rat 22 , showed terminal performances of at least $75 \%$ avoidance. The substantial dip in the curves for rats 17 and 22 over the first few training days suggests that their initial avoidance performances may have been due, in part, to agitated behavior induced by the shocks.

As indicated in the procedure, once the high-shock condition was in effect, an animal could shift control to the low-shock condition by pressing the lever twice with an IRT no greater than $15 \mathrm{sec}$. An index of escape performance for each animal is provided by the mean number of responses per high-intensity shock. The greater the value of this index, the briefer does the animal's exposure to the high-shock condition tend to be on each occasion when that condition is in effect. There was a substantial relationship between the escape and avoidance performances of the animals. A Spearman rho of $.73(p<.02)$ was obtained between the escape index and the percentage which low-intensity shocks constituted of all shocks received. Further details of the performance of rats under the training procedure of the present experiment may be found in the study by Bersh and Alloy (1978).

During the training phase, the yoked animals responded very little. The mean number of leverpresses per 100-min session ranged from .33 to 35.9 for those tested at the low intensity and from 1.2 to 40.2 for those tested at the high intensity. The group means were 14.2 and 15.9 , respectively.

\section{Testing}

The test data are presented in Figure 2 as mean FR 2 escape latencies over blocks of five trials for each of the six groups of the experiment. The mean escape latencies over the five FR 1 trials which preceded FR 2 testing are also shown. Both the $Y$ and $A$ groups were slower to escape than the $\mathrm{N}$ groups during the initial FR 1 trials, particularly at the low test intensity. In addition, the yoked rats tested at the low intensity, even during the initial five trials, became progressively worse, while those tested at the high intensity, after an initial improvement, also showed a trend toward increased latency. A 3 by 2 by 5 repeated measures analysis of variance performed on the FR 1 latencies revealed significant Training Condition $[\mathrm{F}(2,30)=4.05, \mathrm{p}<.03]$, Training Condition by Trials $[\mathrm{F}(8,120)=2.27, \mathrm{p}<.03]$, and Trials by Test Intensity $[F(4,120)=3.90, p<.005]$ effects, while the Training Condition by Test Intensity interaction approached significance $[\mathrm{F}(2,30)=2.95, \mathrm{p}<$ .07]. A Newman-Keuls post hoc comparison among the training conditions confirmed the slower escape by the avoidance and yoked animals than by the no-shock animals $(p<.05)$.

As Figure 2 shows, the FR 2 escape performance of the yoked groups was worse than that of the avoidance and no-shock groups. At the low test in-

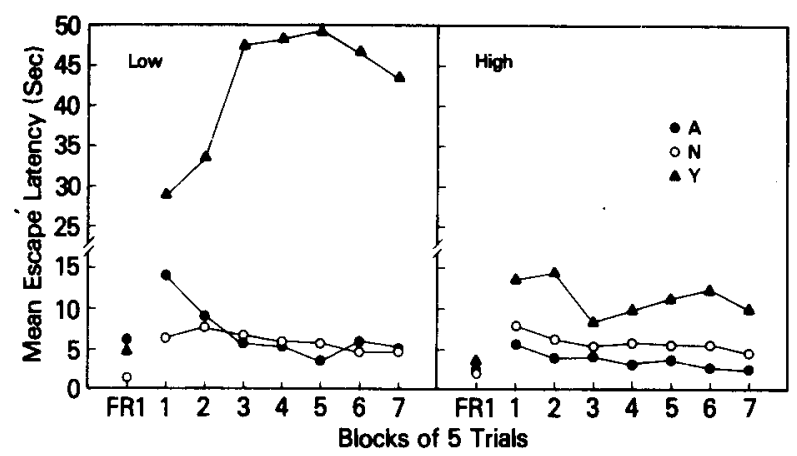

Figure 2. Mean latency to escape across blocks of five trials during the shuttlebox eacape test for animals given avoidance (A), yoked (Y), or no (N) shock pretraining. The left panel provides data for the animals tested at the low shock Intensity $(.75 \mathrm{~mA})$, and the right panel, data for the animals tested at the high shock intensity (1.6 mA). 
tensity, the difference was striking and, in fact, the yoked animals showed a reverse learning curve of the type often reported in learned helplessness studies (e.g., Kelsey, 1977; Seligman \& Beagley, 1975; Seligman \& Maier, 1967). On the other hand, the escape performance of the other rats ( $A$ and $N$ ) at this intensity, with the exception of the first block of five trials, was virtually identical. While the yoked rats tested at the high shock intensity escaped with substantially shorter latencies than rats tested at the low intensity they still failed to match the performances of the other two groups tested at this intensity. Furthermore, the escape performance of the avoidance rats was systematically better than that of the noshock rats. In fact, the three groups tested at the high intensity did not overlap at all in their FR 2 escape latencies. Thus, within each triad, the escape latency of the avoidance animal was less than that of the noshock animal, which, in turn, was less than that of the yoked animal.

These observations were supported by a 3 by 2 by 7 repeated measures analysis of variance which yielded significant main effects for Training Condition $[F(2,30)=73.57, p<.001]$ and Test Intensity $[F(1,30)$ $=48.76, \mathrm{p}<.001]$, significant Training Condition by Test Intensity $[F(2,30)=35.67, p<.001]$ and Training Condition by Trial Block $[\mathrm{F}(12,180)=$ $3.19, \mathrm{p}<.001$ ] double interactions, and a significant Training Condition by Test Intensity by Trial Block triple interaction $[F(12,180)=4.33, p<.001]$. Interpretation of the significant main effects and double interactions is difficult without further analysis of the significant triple interaction. To analyze the triple interaction, Training Condition by Trial Block analyses of variance were performed separately for the low and high test intensities. The Training Condition by Trial Block analysis of variance performed at the low test intensity revealed a significant main effect for Training Condition $[\mathrm{F}(2,15)=59.92, \mathrm{p}<.001]$ and a significant Training Condition by Trial Block interaction $[\mathrm{F}(12,90)=4.93, \mathrm{p}<.001]$. The simple main effects test (Winer, 1962) was used to analyze the interaction. Simple main effects for Training Condition were significant at each Trial Block (ps $<.001$, except B1, where $\mathrm{p}<.005$ ). NewmanKeuls showed that Group Y tested at the low intensity was significantly slower for each trial block than Groups A and N (ps $<.01$ ) and that Group A was significantly slower than Group $N$ at Block $1(p<.05)$. Simple main effects for Trial Block showed a significant increase in latency for Group $Y(p<.001)$. Newman-Keuls indicated that the latency was greater for each of the last four blocks than for each of the first two blocks (ps $<.01$ ). At the high test intensity, the Training Condition by Trial Block interaction was not significant. However, the main effect for Training Condition was reliable $[\mathrm{F}(2,15)=15.58$, $\mathrm{p}<.001$ ]. Newman-Keuls showed that Group $\mathrm{Y}$ was significantly slower to escape than Groups $A(p<.01)$ and $N(p<.05)$. Although the difference between Groups $A$ and $N$ failed to reach significance $(p<.10)$, the fact that their latencies did not overlap, as indicated above, suggests that the performance of Group A was, indeed, superior. The Mann-Whitney $U$ test supported this impression $(U=0, p=.001)$.

Further evidence of massive interference for the yoked rats at the low test intensity is provided by the frequency with which they failed to escape. There was a minimum of 8 and a maximum of 34 failures to escape out of 35 trials for these rats. A failure to escape, as noted in the procedure, exposed the animal to continuous shock for $60 \mathrm{sec}$. A 3 by 2 analysis of variance on the number of failures yielded a pattern of significant effects which was essentially the same as that obtained for FR 2 escape latencies. An examination of the failures to escape indicates that they were largely the result of failure to make the first crossing response. Of a total of 102 failures, 88 represented failures to make the initial response. Once an animal had crossed the first time, the probability of completing the FR 2 response was very high (.89).

A 3 by 2 by 5 repeated measures analysis of variance was performed to analyze escape latencies for the first block of five FR 2 test trials separately. The purpose was to determine whether the inferior performance of the yoked rats was already in evidence. These data indicate that the yoked rats were slower to escape than either avoidance or no-shock rats (ps $<.05)$ at both test intensities from the outset. Group A rats tested at the low intensity also were initially slower to escape than Group $N$ rats $(p<.01)$, but the differences had already narrowed by the end of the first trial block.

\section{DISCUSSION}

All animals in both avoidance groups, except perhaps Rat 10, demonstrated substantial control over shock intensity, with a terminal performance of at least $70 \%$ avoidance of high-intensity shock. This occurred despite the fact that they received all scheduled shocks and that the low-intensity shock was aversive in its own right. Shock of this intensity level $(.75 \mathrm{~mA})$ has often been used to develop and maintain escape and avoidance behavior (e.g., Bersh \& Lambert, 1975).

A clear-cut interference effect was obtained for animals exposed to shocks under conditions where all shock characteristics were response-independent. These are, of course, the conditions of shock exposure for inescapably shocked animals in learned helplessness studies (Maier \& Seligman, 1976). Both yoked groups were significantly slower to make an FR 2 
escape response in a shuttlebox test situation than were the avoidance and no-shock groups. In fact, there was no overlap between the mean latencies of the yoked animals and those for their avoidance and no-shock partners at each test intensity. The interference effect was especially pronounced for Group $Y$ tested at the low shock intensity $(.75 \mathrm{~mA})$, as shown by an average failure rate of about $50 \%$ of the 35 test trials. Interference of this magnitude is atypically large for rat helplessness experiments (e.g., Looney \& Cohen, 1972; Maier, Albin, \& Testa, 1973; Maier \& Testa, 1975; Seligman \& Beagley, 1975; Seligman, Rosellini, \& Kozak, 1975), and is especially noteworthy, since rats were exposed to shocks of brief duration $(.5 \mathrm{sec})$ during training. Glazer and Weiss $(1976 \mathrm{a}, 1976 \mathrm{~b})$ have argued that nontransient interference effects are the result of animals having learned during training to become inactive due to adventitious reinforcement of lowered activity at the moment of shock termination. They have claimed that shocks of at least $5 \mathrm{sec}$ duration are required to produce such "learned inactivity." Perhaps the large number of shocks in the present experiment $(1,000$ per session for a minimum of nine sessions) and/or their density (an average of about $10 / \mathrm{min}$ ) compensated for their brief duration. However, similar interference effects have been reported by Goodkin (1976) with .5-sec footshock and by Kelsey (1977) with tailshock, the average duration of which ranged from 2.9 to $4.1 \mathrm{sec}$. Accordingly, exposure to shocks of long duration is certainly not a prerequisite for subsequent interference with escape. In addition, Jackson, Maier, and Rapaport (1978, Experiment 4) have reported that even with the use of long-duration shocks ( $5 \mathrm{sec}$ ), prior exposure to inescapable shock produces an associative deficit which cannot be accounted for in terms of inactivity.

Animals that could control shock intensity, though not shock occurrence, showed some interference during FR 1 and the first five FR 2 trials, but then performed as well as no-shock animals at the low test intensity. At the high test intensity, the avoidance rats escaped even more quickly than their no-shock partners. Thus, control of shock intensity was sufficient to prevent interference with subsequent acquisition of escape behavior, despite the fact that such control simply exposed the animals to shocks still intense enough to be aversive without eliminating any shocks. Furthermore, differences in the degree of control over intensity exercised by Group A animals did not affect their escape performance at the low test intensity so that control as incomplete as that shown by rat $10 \mathrm{~A}$ prevented interference as effectively as that manifested by animals which met the avoidance criterion.

The type of interference manifested by the yoked animals has been interpreted in two major ways. Ac- cording to learned helplessness theory (Maier \& Seligman, 1976), such interference is attributable to the expectation that responses and outcomes are independent. This leads to both response initiation and associative deficits. Response initiation deficit consists of reduced incentive to engage in voluntary activity, while associative deficit involves difficulty in learning that responses and outcomes are related. An alternative account of the interference effect is provided by the learned response competition approach (Anisman \& Waller, 1973; Bracewell \& Black, 1974; Glazer \& Weiss, 1976a, 1976b; Levis, 1976). This assumes that animals exposed to inescapable shock acquire patterns of motor behavior which serve to reduce the severity of the shock. Such patterns then transfer to situations where escape and/or avoidance is possible and compete with the requisite escape or avoidance response.

Both forms of interpretation account reasonably well, not only for the present interference effect, but also for the greater interference found at the low test intensity. The higher aversive drive produced by the 1.6-mA test shocks serves to overcome, in part, the response initiation deficit. Alternatively, since the avoidance performance during training of the $A$ rats exposed their yoked partners predominantly to the low (.75-mA) shocks, the low-intensity test condition was more similar to training and, therefore, favored transfer of the competing behavior. It is noteworthy that Rosellini and Seligman (1978) found interference for rats exposed to inescapable shock only when the training and test shock intensities were alike.

The fact that yoked animals escaped on all FR 1 trials might be attributed by both approaches to nearreflexive reactions to shock (e.g., Maier et al., 1973; Seligman \& Beagley, 1975). A shock-elicitation basis for FR 1 performance is not without difficulties, however. At the low test intensity, yoked rats showed a significant increase in latency even during the five FR 1 trials. Why should elicitation become less effective with exposure to the FR 1 condition? Furthermore, FR 1 latencies at the high test intensity were not significantly shorter than at the low test intensity for the yoked or no-shock animals, although shock intensity was more than twice as great. Latencies for the avoidance rats did decrease significantly, thus countering the possible argument that the higher shock intensity increased the tendency to "freeze." The finding that $89 \%$ of all FR 2 failures at the low intensity were due to failure to make the first response also contradicts a pure elicitation idea. The suggestion is strong, therefore, that FR 1 involved more than shock elicitation. Though it is not possible in the present experiment to separate associative deficit from response initiation deficit, the associative deficit hypothesis seems capable of accounting for the increases in latency for $\mathrm{Y}$ rats during low-test- 
intensity FR 1 and FR 2 trials better than does response competition.

There are several other aspects of the data which appear to be more supportive of learned helplessness theory than of learned response competition. FR 2 interference was considerably greater than FR 1 interference, particularly at the low test intensity. Learned helplessness theory suggests that this is due to the fact that FR 2 is a more voluntary form of behavior than FR 1, even if the latter involves more than shock-induced reflexive behavior. On the other hand, response competition should have been less for the FR 2 trials than for the FR 1 trials, because the longer durations of shock exposure inherent in FR 2 made that condition less similar to the brief $(.5 \mathrm{sec})$ shocks of the training phase. Less similarity between training and test presumably implies less transfer of competing motor patterns acquired during training.

The test performance of the avoidance rats and of the yoked rats in relation to the training performance of their avoidance partners also seems to pose more difficulty for response competition than for learned helplessness. At the low test intensity, the avoidance rats showed interference compared with the no-shock rats both during FR 1 and during the first five FR 2 trials. Yet they escaped as quickly as the no-shock rats during the remaining FR 2 trials. Perhaps the early interference was due to response competition, but, unlike the yoked rats, this was overcome. Learned helplessness theory can attribute this to their control experience during training which would mitigate response initiation deficit and prevent associative deficit. The response competition approach might suggest that the training engendered active responding by the avoidance rats and inactivity or freezing by the yoked rats. Unfortunately, observation of the yoked rats during training was precluded by the fact that the experimental chamber was dark. Accordingly, their level of activity is unknown. Nevertheless, leverpressing, thoroughly acquired by the avoidance rats, favors rearing or jumping behavior, just as antagonistic to crossing behavior as inactivity. Moreover, an "activity" vs. "inactivity" argument is further weakened by the finding of Lawry, Lupo, Overmier, Kochevar, Hollis, and Anderson (1978) that, for either dogs or rats exposed to inescapable ac shock (the type of shock used here), no correlation existed between activity during preshock and subsequent interference with avoidance.

Finally, there was no correlation in the present experiment between the training performance of avoidance rats and the test performance of either avoidance rats or their yoked partners. Learned helplessness theory might reasonably maintain that no interference will result as long as animals exert some minimum level of control during training. But learned response competition bases the magnitude of transfer effects upon the degree of similarity between training and test conditions. Poorer avoidance performance by avoidance rats exposed their yoked partners to a larger proportion of high shocks, thus reducing the similarity of the low test intensity condition to the training condition. As noted, however, this did not affect the test performance of either avoidance or yoked rats.

Perhaps the most striking evidence in favor of a learned helplessness vs. a learned response competition account is the finding that control of shock intensity by avoidance rats during training facilitated FR 2 shuttlebox escape at the high test intensity. Facilitation has also been reported by Braud, Wepman, and Russo (1969) for mice, by Hannum, Rosellini, and Seligman (1976) for weanling rats, and by Goodkin (1976) for adult rats. Even if it is assumed that leverpressing involves less response competition with shuttling than the behavior that may have been acquired by the yoked rats, it is unreasonable to suppose that its acquisition during training would facilitate shuttling. On the other hand, such facilitation is compatible with learned helplessness theory by assuming that specific experience with control of aversive events may increase an animal's sensitivity to future correlations between behavior and outcome (e.g., Goodkin, 1976). In the present experiment, the facilitation effect may have been due to the specific experience of Group A animals with escape from the high-intensity shock. Support for this suggestion is provided by the existence for that group of a significant positive correlation between the mean number of low-intensity shocks during the last 4 days of avoidance training as a percentage of total shocks and the mean FR 2 escape latencies (Spearman rho $=.89, \mathrm{p}<.05)$. That is, the poorer an animal's avoidance performance and, consequently, the greater its exposure to high shock, the more rapidly it tended to escape from high shock during the shuttlebox test. An interpretation in terms of simple habituation or a reduced tendency to freeze in the presence of shock appears inadequate in view of the inferior performance of the yoked rats tested at the high intensity and the absence of a correlation between their mean escape latencies and the performance during training of their avoidance partners. Besides, shock habituation might be expected to lower the aversive drive produced by the high shock, and therefore, to result in inferior test performance by animals whose avoidance performance was inferior. At the same time, an interpretation in terms of a sensitization effect also may be ruled out by the lack of correlation noted above.

Under both test conditions, the performance of the yoked rats was unrelated to the terminal performance during training of their avoidance partners, so that substantial variations in high-shock exposure for the 
yoked animals at the end of the training phase made no difference in their escape performance. This supports the argument that the interference effect of exposure to uncontrollable shock upon subsequent escape cannot be ascribed to yoked design bias (Maier \& Jackson, 1977). It is quite unlikely that yoked rats for which shock was relatively effective would have as their avoidance partners only rats for whom shock was relatively ineffectve, and vice versa. Furthermore, all yoked rats showed interference with escape in the test situation.

Maier and Seligman (1976) have identified uncontrollability as the primary condition for the type of interference with subsequent acquisition known as learned helplessness. They have defined uncontrollability as a condition represented by any point on the equiprobability diagonal of a two-dimensional space generated by the probability of reinforcement given the occurrence of a response vs. the probability of reinforcement given the absence of that response. Presumably the outcome or reinforcer, like the response, must be the same in the equiprobability condition. If this is the case, then potentially relevant characteristics of the reinforcer other than occurrence are implicitly incorporated in the definition of uncontrollability. However, it is strictly an empirical question to determine whether any specific characteristic of a reinforcer must be independent of behavior for learned helplessness to occur. The results of the present experiment clearly indicate that shock intensity must be independent of behavior to produce interference with subsequent escape performance. Equiprobability of shock occurrence and equal duration are not sufficient. Such a demonstration would be trivial if control involved reduction of intensity to a nonaversive level. That the lower shock intensity $(.75 \mathrm{~mA})$ of the training phase was aversive is completely demonstrated by the perfect shuttlebox escape performance and the relatively small mean latencies of the avoidance and no-shock groups at the .75-mA test intensity. Of course, degree of control over other characteristics of inescapable shock (e.g., duration and quality) may also be relevant to the specification of the conditions which lead to learned helplessness.

A general issue is raised by research of this kind. If control of a characteristic of a reinforcer is sufficient to produce acquisition and maintenance of behavior, will such control also suffice to prevent learned helplessness? For example, will control of aversiveness to a degree that results in the acquisition and maintenance of escape/avoidance behavior prevent interference with subsequent escape/avoidance performance? Or are there shock parameters, less salient than intensity, which, though capable of supporting escape/avoidance behavior, might still lead to subsequent interference, perhaps less pronounced than for the case of total lack of control? Questions of this kind suggest that a complete specification of control, including specification of degree of lack of control necessary and sufficient for learned helplessness, may require an $\mathbf{n}$-dimensional space for its representation, with the value of $\mathbf{n}$ a matter for empirical determination.

The finding of the present experiment that control over shock intensity alone prevents interference with the subsequent acquisition of escape behavior suggests that control over any salient characteristic of a reinforcer may be sufficient for "immunization" (Seligman \& Maier, 1967; Seligman et al., 1975). In view of the hypothesized link between learned helplessness and depression (e.g., Abramson, Seligman, \& Teasdale, 1978; Seligman, 1975), there may be therapeutic implications in the sufficiency of partial control over reinforcers for "immunization."

\section{REFERENCES}

Abramson, L. Y., Seligman, M. E. P., \& Teasdale, J. Learned helplessness in humans: Critique and reformulation. Journal of Abnormal Psychology, 1978, 87, 49-74.

Anisman, H. \& Waller, T. G. Effects of inescapable shock on subsequent avoidance performance: Role of response repertoire changes. Behavioral Biology, 1973, 9, 331-355.

Bersh, P. J. \& Alloy, L. B. Avoidance based on shock intensity reduction with no change in shock probability. Journal of the Experimental Analysis of Behavior, 1978, 30, 293-300.

Bensh, P. J. \& LAmberT, J. V. The discriminative control of free-operant avoidance despite exposure to shock during the stimulus correlated with nonreinforcement. Journal of the Experimental Analysis of Behavior, 1975, 23, 111-120.

Bracewell, R. J. \& Black, A. H. The effects of restraint and noncontingent pre-shock on subsequent escape learning in the rat. Learning and Motivation, 1974, 5, 53-69.

Braud, W., Wepman, B., \& Russo, D. Task and species generality of the "helplessness" phenomenon. Psychonomic Science, $1969,16,154-155$.

Glaze R, H. I. \& Weiss, J. M. Long term and transitory interference effects. Journal of Experimental Psychology: Animal Behavior Processes, 1976, 2, 191-201.(a)

Glazer, H. I. \& WEISs, J. M. Long-term interference effect: An alternative to "learned helplessness." Journal of Experimental Psychology: Animal Behavior Processes, 1976, 2, 201-213. (b)

Goodkin, F. Rats learn the relationship between responding and environmental events: An expansion of the learned helplessness hypothesis. Learning and Motivation, 1976, 7, 382-393.

Hannum, R. D., Rosellini, R. A., \& Seligman, M. E. P. Retention and immunization of learned helplessness from weaning to adulthood. Developmental Psychology, 1976, 12, 449-454.

Hiroto, D. S. \& Seligman, M. E. P. Generality of learned helplessness in man. Journal of Personality and Social Psychology, 1975, 31, 311-327.

Jackson, R. L., Maien, S. F., \& RAPAPORT, P. M. Exposure to inescapable shock produces both activity and associative deficits in the rat. Learning and Motivation, 1978, 9, 69-98.

KELSEY, J. E. Escape acquisition following inescapable shock in the rat. Animal Learning \& Behavior, 1977, 5, 83-92.

Lawry, J. A., Lupo, V., Overmier, J. B., Kochevar, J., Hollis, K. L., \& ANDERson, D. C. Interference with avoidance behavior as a function of qualitative properties of inescapable shocks. Animal Learning \& Behavior, 1978, 6, 147-154. 
LEvis, D. J. Learned helplessness: A reply and an alternative S-R interpretation. Journal of Experimental Psychology: General, 1976, 105, 47-65.

Looney, T. A., \& Cohen, P. S. Retardation of jump-up escape responding in rats pretreated with different frequencies of noncontingent electric shocks. Journal of Comparative and Physiological Psychology, 1972, 78, 317-322.

Maier, S. F., Albin, R. W., \& Testa, T. J. Failure to learn to escape in rats previously exposed to inescapable shock depends on nature of escape response. Journal of Comparative and Physiological Psychology, 1973, 85, 581-592.

MaIER, S. F., \& JACKSON, R. L. The nature of the initial coping response and the learned helplessness effect. Animal Learning \& Behavior, 1977, 5, 407-414.

Maier, S. F., \& Seligman, M. E. P. Learned helplessness: Theory and evidence. Journal of Experimental Psychology: General, 1976, 105, 3-46.

Maier, S. F., Seligman, M. E. P., \& Solomon, R. L. Pavlovian fear conditioning and learned helplessness. In B. A. Campbell \& R. M. Church (Eds.), Punishment. New York: AppletonCentury-Crofts, 1969.

Maier, S. F., \& Testa, T. J. Failure to learn to escape by rats previously exposed to inescapable shock is partly produced by associative interference. Journal of Comparative and Physiological Psychology, 1975, 88, 554-564.
Rosellini, R. A., \& Seligman, M. E. P. Role of shock intensity in the learned helplessness paradigm. Animal Learning \& Behavior, 1978, 6, 143-146.

Seligman, M. E. P. Helplessness. San Francisco: Freeman, 1975.

Seligman, M. E. P., \& Beagley, G. Learned helplessness in the rat. Journal of Comparative and Physiological Psychology, 1975, 88, 534-541.

Seligman, M. E. P., \& Maier, S. F. Failure to escape traumatic shock. Journal of Experimental Psychology, 1967, 74, $1-9$.

Seligman, M. E. P., Maier, S. F., \& Solomon, R. L. Unpredictable and uncontrollable aversive events. In F. R. Brush (Ed.), Aversive conditioning and learning. New York: Academic Press, 1971.

Seligman, M. E. P., Rosellini, R. A., \& Kozak, M. J. Learned helplessness in the rat: Time course, immunization and reversibility. Journal of Comparative and Physiological Psychology, 1975, 88, 542-547.

Wine R, B. J. Statistical principles in experimental design. New York: McGraw-Hill, 1962.

(Received for publication June 19, 1978; revision accepted October $18,1978$. 